\title{
Lubricating performances of graphene oxide and onion-like carbon as water-based lubricant additives for smooth and sand-blasted steel discs
}

\author{
Fenghua SU*, Guofu CHEN, Ping HUANG \\ School of Mechanical and Automotive Engineering, South China University of Technology, Guangzhou 510641, China \\ Received: 07 March 2018 / Revised: 20 April 2018 / Accepted: 02 August 2018 \\ (C) The author(s) 2018. This article is published with open access at Springerlink.com
}

\begin{abstract}
Graphene oxide (GO) nanosheets and onion-like carbon (OLC) nanoparticles were synthesized from natural graphite powder and candle soot, respectively, and characterized by transmission electron microscopy and Raman spectroscopy. The lubricating performances of GO and OLC as lubricant additives in water were comparatively evaluated using a ball-on-disc tribometer. The effects of sand blasting of a steel disc on its morphology and tribological property were evaluated. The results show that the two nanomaterials, GO and OLC, when used as lubricant additives in water effectively reduce the friction and wear of the sliding discs, which is independent of the disc surface treatment. On applying heavy loads, it is observed that GO exhibits superior friction-reducing and anti-wear abilities compared to those of OLC - a trace amount of GO can achieve a lubricating ability equivalent to that of an abundant amount of OLC. Furthermore, it is observed that sand blasting cannot improve the wear resistance of the treated steel disc, even though the hardness of the disc increased after the treatment. The possible anti-wear and friction-reducing mechanisms of the GO and OLC as lubricant additives in water are discussed based on results for the wear surfaces obtained by scanning electron microscopy, Raman spectroscopy, and X-ray photoelectron spectroscopy
\end{abstract}

Keywords: graphene oxide; onion-like carbon; lubricant additive; friction and wear

\section{Introduction}

Water is an environment-friendly lubricant with a high cooling capacity. However, its low viscosity and corrosive property make it unacceptable in most tribological applications. Therefore, studies have been performed to improve the lubricating performance of water-based lubricants [1-3]. A promising approach is to develop high-quality additives without environmentally harmful compositions. Recently, various carbon nanomaterials, such as carbon nanotubes, graphene, graphite alkyne, diamond, and carbon black, were extensively employed as lubricant additives in water and exhibited superior anti-wear and friction-reducing properties [4-10]. Peng et al. [5] confirmed that
SDS-functionalized multi-walled carbon nanotubes (MWCNTs) were an effective lubricant additive in water, which significantly reduced the friction coefficient and wear rate of friction pairs. Kinoshita et al. [6] reported that graphene oxide (GO) nanosheets were easily attached onto friction surfaces in water and formed a protective coating, leading to significant improvement in the friction-reducing and anti-wear performances. Elomaa et al. [7] reported enhancements in the friction-reduction and wear resistance properties of a water-based lubricant with a GO additive, as GO nanosheets were embedded into counterpart ball surfaces and thus absorbed more water molecules into the contact surfaces.

In addition to the above carbon nanomaterials,

* Corresponding author: Fenghua SU, E-mail: fhsu@scut.edu.cn 
onion-like carbon (OLC) attracted significant attention in different fields, particularly in the field of energy storage [11-16]. OLC exhibited great potentials for applications in the field of tribology [17-23], mainly as it was considered a closed quasi-spherical form of graphite, which is a well-known solid lubricant. Matsumoto et al. [17] reported that OLC nanoparticles as an additive in oil exhibited a better frictionreducing ability than that of carbon nanotubes in the contact pressure range of 0.51 to $1.10 \mathrm{GPa}$ [17]. Joly-Pottuz et al. [21] systematically compared the lubricating performances of carbon "nanoonions" and graphite powders as additives in a synthetic base oil. They confirmed that the formed tribofilm by carbon "onions" could trap large abrasive wear particles and convert them into ultrafine lubricious iron oxides, thus preventing the contact surfaces from further abrasive wear. In addition, OLC nanoparticles were verified by Wei et al. as an effective oil-based lubricant additive in water [23].

The surface enhancement treatment was also important in the improvement in the friction and wear properties. The sand-blasting treatment was widely used for surface strengthening, surface modification, surface clearing, rust removal, etc. [24]. It was suitable for the treatment of hard and brittle materials, ductile metals, alloys, and nonmetallic materials, and could provide perfect surface treatments to all types of workpieces, from hull, steel structure, and container, to watchcase, button, and inject needle. Guan et al. [25] confirmed that sand blasting significantly improved the microhardness and wear resistance of an aluminum surface owing to the formation of a nanocrystalline layer.

In this study, GO and OLC were prepared and employed as water-based lubricant additives. The tribological properties of the two carbon nanomaterials are comparatively investigated using a ball-on-disc tribometer. The effects of sand blasting of a stainless disc on the friction and wear behaviors were evaluated under different lubricating conditions. In addition, the anti-wear and friction-reducing mechanisms of GO and OLC as lubricant additives in water are discussed by analyzing the wear surfaces with scanning electron microscopy (SEM), X-ray photoelectron spectroscopy (XPS), and Raman spectroscopy.

\section{Materials and methods}

\subsection{Synthesis of GO and OLC}

GO was synthesized from natural graphite powders (Qingdao Dongkai Co., Ltd., China) using a modified Hummers' method [26, 27]. Details of the synthesis process are presented in our previous report [28]. OLC was synthesized from candle soot with an improved approach [23, 29]. First, candle soot was deposited on a thoroughly cleaned glass plate from the tip of the flame of a burning candle. The glass plate $(4 \mathrm{~cm} \times$ $6 \mathrm{~cm}$ ) moved horizontally back and forth during the deposition process, so that more candle soot could be deposited on the substrate. The deposition process lasted $3 \mathrm{~min}$, and then the candle soot was mechanically scraped from the glass substrate and collected in a glass bottle. Subsequently, the collected candle soot was annealed at $430{ }^{\circ} \mathrm{C}$ for $3 \mathrm{~h}$ in an air-atmosphere muffle furnace to completely oxidize the residual wax and organic compounds. The carbon nanomaterial OLC was obtained after the heat treatment.

\subsection{Characterizations}

The morphologies of GO and OLC were analyzed using high-resolution transmission electron microscopy (TEM, JEOL JEM-2010F). Structural informations of GO and OLC were obtained by a Raman spectroscopy measurement using a Dilor Labram-1B multichannel confocal microspectrometer with an excitation laser wavelength of $633 \mathrm{~nm}$. The morphologies of the steel disc surfaces and wear scar surfaces were characterized using a Quanta 200 SEM. The surface roughness and topographies of the steel discs were measured using a Talysurf CLI 1000 surface profile measurement system. The microhardness was measured using a Vickers microhardness tester at a load of $300 \mathrm{~g}$ applied for $10 \mathrm{~s}$. The average value from five replicates for each type of specimen was reported.

\subsection{Sand blasting of the steel disc}

Sand blasting was carried out by a sand-blasting machine (Ningbo XinOu Sand-blasting Machinery Co., Ltd., China) with silica particles with diameters of $100-300 \mu \mathrm{m}$. The treatment process lasted $20 \mathrm{~s}$ at a pressure of $0.4 \mathrm{MPa}$ with a constant working distance 
of $20 \mathrm{~cm}$. After the sand-blasting treatment, the surface roughness $\left(R_{\mathrm{a}}\right)$ of the modified steel disc increased to approximately $0.2 \mu \mathrm{m}$. The polished steel disc with an $R_{\mathrm{a}}$ value of approximately $0.01 \mu \mathrm{m}$ is denoted as the smooth sample. The disc treated by sand blasting is denoted as the sand-blasted sample.

\subsection{Friction and wear behaviors}

The lubricating performances of the GO nanosheets and OLC nanoparticles as lubricant additives in water were evaluated with a ball-on-disc tribometer (MS-T3000, Lanzhou Huahui Instrument Technology Co., Ltd., China) under room-temperature and humid conditions. The sliding between the frictional pairs was controlled by pressing the upper stationary ball against the lower rotating disc. Figure 1 shows a schematic of the tribo-test configuration. The disc used for tribo-tests was composed of 304 stainless steel with dimensions of $20 \mathrm{~mm} \times 40 \mathrm{~mm} \times 4 \mathrm{~mm}$. The upper ball was made of GCr15 bearing steel with a diameter of $4 \mathrm{~mm}$ and hardness of approximately 61-65 HRC. The tribo-tests were performed at a constant rotation speed of $200 \mathrm{rpm}$ and different loads of 2-10 N for $20 \mathrm{~min}$. Table 1 shows the corresponding Hertzian contact pressures calculated from the applied loads. The diameter of the wear track on the disc was $12 \mathrm{~mm}$. The dry friction test was performed under ambient air, while the wet friction test was performed in pure water or water-based lubricant containing GO or OLC. The lubricant additive, GO or OLC, with a desired concentration was added in water and ultrasonically dispersed for $30 \mathrm{~min}$ to achieve a homogeneous dispersion. The ball-on-disc was entirely submerged into the as-prepared water-based lubricant during the rubbing process. After the tribo-test, the steel disc was ultrasonically cleaned with anhydrous ethanol, and then dried in air. The wear surface of the disc was studied by profilometry and SEM. The width and depth of the wear track on the disc were automatically converted into wear volume by the equipment software. The wear rate of the disc was calculated by: $K=V /(S F)$, where $V$ is the wear volume $\left(\mathrm{mm}^{3}\right), S$ is the total sliding distance $(\mathrm{m})$, and $F$ is the normal load $(\mathrm{N})$. The chemical composition of the wear scar surface was analyzed by Raman spectroscopy and XPS (Kratos Axis Ultra DLD).

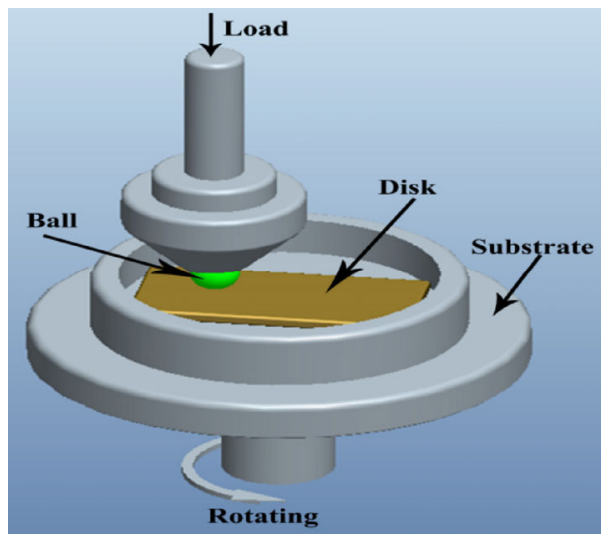

Fig. 1 Schematic of the tribo-test configuration.

Table 1 Applied loads and corresponding Hertzian contact pressures for tribo-tests.

\begin{tabular}{cccccc}
\hline Applied load $(\mathrm{N})$ & 2 & 4 & 6 & 8 & 10 \\
\hline $\begin{array}{c}\text { Corresponding } \\
\text { Hertzian contact } \\
\text { pressure (MPa) }\end{array}$ & 1039 & 1309 & 1498 & 1649 & 1776 \\
\hline
\end{tabular}

\section{Results and discussion}

\subsection{Microstructures and morphologies of the GO and OLC}

Figure 2 shows the microstructures and morphologies of the GO and OLC. As shown in Figs. 2(a) and 2(b), the GO nanosheets were highly transparent with folds at the edges, suggesting the ultrasmall thicknesses of the nanosheets. As shown in Figs. 2(c) and 2(d), the OLC nanoparticles had spherical shapes and onion-like structures with diameters of 30 to $60 \mathrm{~nm}$. The cores of the OLC nanoparticles were not hollow; they exhibited a continuation of the closed cage structure toward the center, similar with the result reported by Choucair et al. [29].

Raman spectra of the OLC and GO are shown in Fig. 2(e). Graphite exhibits a strong $\mathrm{G}$ peak at $1,570 \mathrm{~cm}^{-1}$ attributed to the first-order scattering of the $E_{2 \mathrm{~g}}$ mode [30]. The D peak at $1,340 \mathrm{~cm}^{-1}$ is assigned to the vibration of carbon atoms with dangling bonds for the in-plane termination of the disordered graphite $[23,31]$. For the OLC, the prominent peaks at $1,340 \mathrm{~cm}^{-1}$ and $1,593 \mathrm{~cm}^{-1}$ corresponded to the $\mathrm{D}$ and $\mathrm{G}$ peaks, respectively. The shift in the $G$ peak occurred owing to the larger size and visible defects [29]. In the case of the GO, the broadened D peak at $1,340 \mathrm{~cm}^{-1}$ was attributed to the 

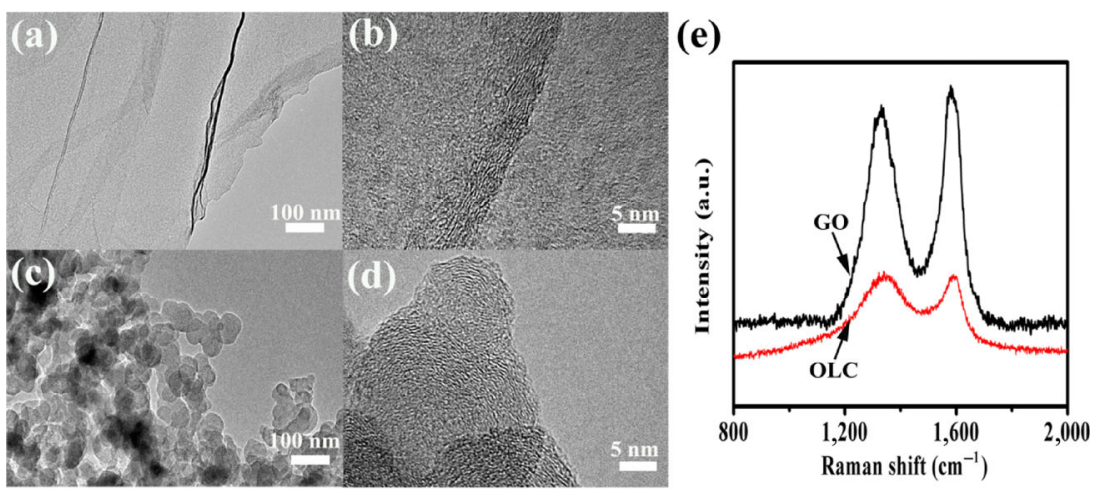

Fig. 2 High-resolution transmission electron microscopy (HR-TEM) images of GO (a, b) and OLC (c, d); Raman spectra of GO and $\operatorname{OLC}(\mathrm{e})$.

reduction in size of in-plane $\mathrm{sp}^{2}$ domains in graphite induced by the creation of defects, vacancies, and distortions of the $\mathrm{sp}^{2}$ domains after the complete oxidation $[32,33]$. The shifted $G$ peak to $1,580 \mathrm{~cm}^{-1}$ was attributed to the oxygenation of graphite [34].

\subsection{Surface morphologies and hardness values of the sand-blasted discs}

The characterizations of the surface structures and morphologies of the smooth and sand-blasted discs are shown at Fig. 3. As shown in Fig. 3(a), the surface roughness increased from $0.01 \mu \mathrm{m}$ for the smooth surface to $0.20 \mu \mathrm{m}$ for the sand-blasted surface. Compared to the smooth surface (Fig. 3(b)), unevensize pits and protuberances were observed on the modified surface after sand blasting (Figs. 3(c) and 3(e)). Figures 3(d) and 3(f) further confirmed that there were large numbers of sharp edges, ridges, and peaks on the surface of the sand-blasted sample, attributed to the surface plastic deformation occurred during the sand-blasting process [35]. The plastic deformation leads to strain hardening, which explains the increased hardness of the sand-blasted surface. As expected, the hardness increased from $336 \mathrm{HV}$ for the smooth surface to $485 \mathrm{HV}$ for the sand-blasted surface, as shown in Table 2.

\subsection{Friction and wear behaviors}

Typical friction-coefficient curves of the smooth and sand-blasted surfaces under different sliding conditions are shown in Figs. 4(a) and 4(b), respectively. As shown in Figs. 4(a) and 4(b), the friction coefficients significantly fluctuated under the dry sliding and
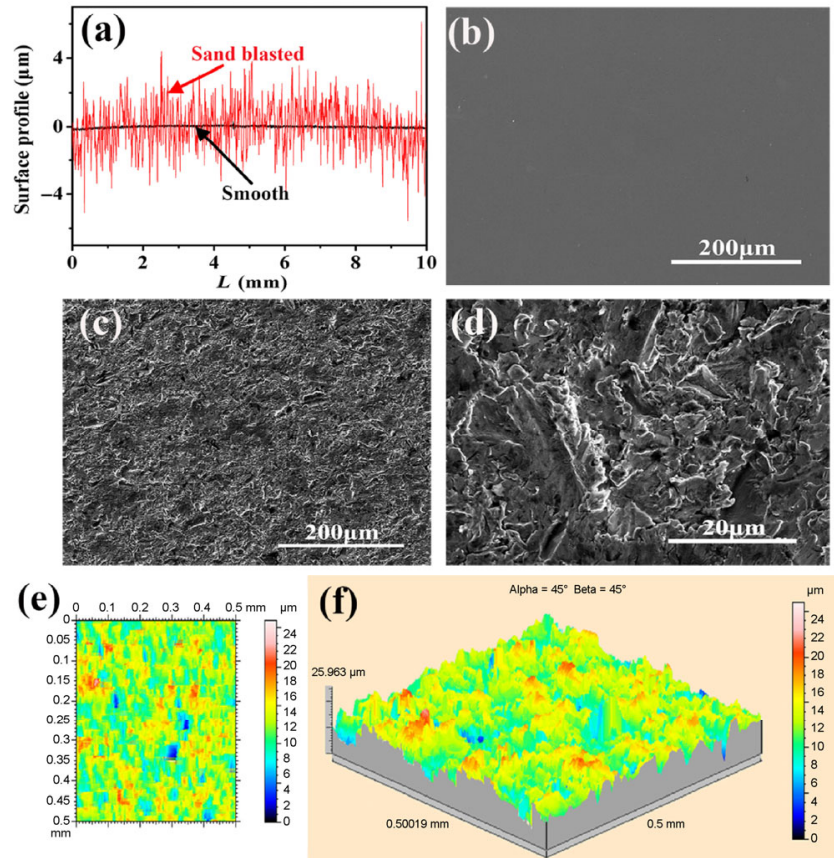

Fig. 3 Surface roughness (a), SEM images of the smooth (b), the sand blasted (c and d) discs, and the surface topography of the sand blasted disc (e: 2D and f: 3D).

Table 2 Hardness of the smooth and sand blasted discs.

\begin{tabular}{ll}
\hline Samples & Hardness (HV) \\
Smooth disc & $336 \pm 8$ \\
Sand blasted disc & $485 \pm 14$ \\
\hline
\end{tabular}

were slightly stabilized when water was introduced for both smooth and sand-blasted surfaces. In contrast, the friction coefficient was very stable throughout the sliding process when the OLC or GO was added in water. Both OLC and GO were effective lubricant additives in water reducing the friction, independent on the treatment of the disc surface. The sand-blasted 

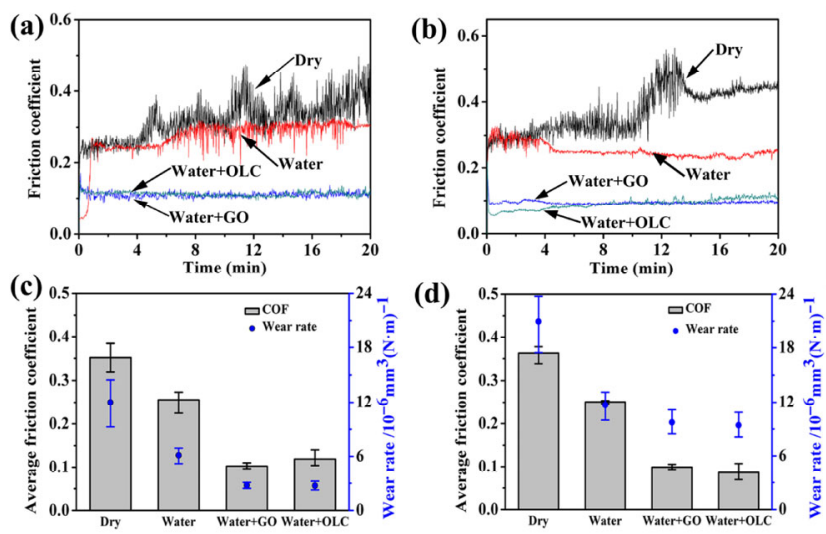

Fig. 4 Typical friction coefficient curves for the smooth surface (a) and the sand blasted surface (b) under the dry sliding and different lubricating conditions. Average friction coefficients and wear rates of the smooth surface (c) and sand blasted surface (d) under dry sliding and different lubricating conditions (load: $2 \mathrm{~N}$, additives concentration: $0.06 \mathrm{wt} . \%$ ).

surface exhibited slightly lower and more stable friction coefficients than those of the smooth surface when they were lubricated by pure, GO-, or OLC-dispersed water, as shown in Figs. 4(a) and 4(b).

The average friction coefficients and wear rates of the smooth and sand-blasted surfaces under different sliding conditions are shown in Figs.4(c) and 4(d). The average friction coefficients were approximately 0.35 for both smooth and sand-blasted surfaces under the dry sliding; they were reduced to 0.25 when pure water was employed as the lubricant. The average friction coefficients remarkably decreased from 0.25 to approximately 0.1 when the GO or OLC was added in the water, which revealed that the two nanomaterials were effective for friction reduction. Figures 4(c) and 4(d) show significant differences in wear rate between the different rubbing surfaces. Unexpectedly, sand blasting increased the wear rates of the disc surfaces under all test conditions, which might be attributed to the increased abrasive wear induced by the rough steel surface after sand blasting. Although the hardness of the disc increased after sand blasting, it was still lower than that of the counterpart GCr15 ball (61-65 HRC). Therefore, the rough surface of the sand-blasted disc was easily scuffed by the hard counterpart ball and formed abrasive grains during the rubbing process, leading to the increased wear rate of this surface. Simultaneously, Figs. 4(c) and 4(d) show that the water-based lubricants significantly reduced the wear rates of the discs, compared to those for the dry sliding. Although the water containing 0.06 wt. $\%$ GO or 0.06 wt.\% OLC did not yield a significant difference in lubricating ability at this sliding condition, it was more effective than the pure water as a lubricant.

Figure 5 shows variations in friction coefficient and wear rate with the increase in the applied load for the smooth surface under different lubricating conditions. The OLC and GO as lubricant additives significantly reduced the friction coefficients under different applied loads, as shown in Fig.5(a). The friction-reducing ability of the GO was superior to that of the OLC for all applied loads. The friction coefficients of these samples steadily increased with the load under the different lubricating conditions. Regarding the variations in wear rate with the increase in the applied load shown in Fig. 5(b), in the case of the GO-dispersed water, the wear rate slightly decreased with the increase in the applied load up to $8.0 \mathrm{~N}$, and then increased with the further increase in the load. However, the wear rate for the sample lubricated by the OLCdispersed water gradually increased with the applied load. Therefore, the OLC was more sensitive to the applied load than the GO for the wear rate reduction. When the applied load was over $4 \mathrm{~N}$, the GO was significantly more effective than the OLC as a lubricant additive in water for wear reduction. Overall, the two nanomaterials, GO and OLC, as lubricant additives in water were effective for friction and wear reductions. The GO exhibited significantly better friction-reducing and anti-wear abilities than those of the OLC, particularly under high applied loads.

The effects of the dispersion concentrations of GO and OLC in water on the friction coefficients and wear rates of the smooth surface are shown in Fig. 6 . Both friction coefficients and wear rates exhibited similar "deep valley" shapes with the increase in the
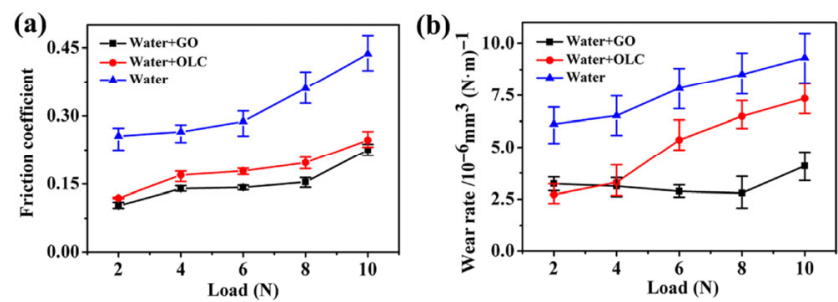

Fig. 5 Effect of applied load on the friction coefficients and wear rates of the smooth disc under different lubricating conditions (additive concentration: $0.06 \mathrm{wt} . \%$ ). 

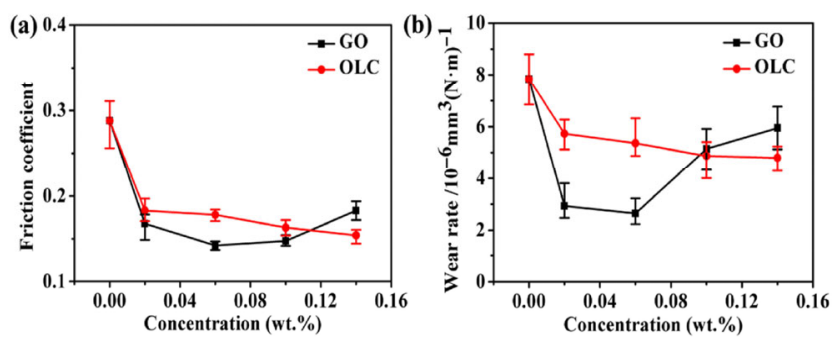

Fig. 6 Effect of the dispersion concentration of GO and OLC in water on the friction coefficients and wear rates of the smooth surface (load: $6 \mathrm{~N}$ ).

GO concentration in water. The optimal concentration of GO in water was approximately $0.02-0.06 \mathrm{wt} . \%$. It is worth noting that both friction coefficient and wear rate slowly decreased with the increase in the OLC concentration in the water. This shows that more OLC should be used to achieve a lubricating performance equivalent to that achieved by a trace amount of GO.

\subsection{Analysis of the wear surfaces}

Figure 7 shows the wear surfaces of the smooth and sand-blasted discs under different sliding conditions. As shown in Figs. 7(a)-7(h), the wear scars on the sand-blasted surfaces were uneven with unstable wear widths, compared to those on the smooth surfaces, which might be attributed to the increased surface roughness and produced asperities by the sand blasting. As shown in Figs. 7(a) and 7(e), the wear surface had wide, deep, and rough wear scars with a large amount of wear debris and few delamination layers, indicating that a severe fatigue, abrasive, and adhesive wear occurred under the dry sliding condition. When the pure water was employed as the lubricant, the wear scar was narrower and smooth, and the wear surface exhibited a few signs of adhesion and fatigue wear (Figs. 7(b) and 7(f)). The widths of the wear scars lubricated with the GO (Figs. 7(c) and 7(g)) and OLC (Fig. 7(d) and 7(h)) dispersed waters were smaller and the surface was quite smooth, compared to those for the lubrication with pure water. Figures $7(\mathrm{k})$ and 7(l) show deeper scratches and severe delamination of the surface layer on the wear surface of the sand-blasted disc, compared to those on the smooth surface (Figs. 7(i) and 7(j)). These results might be attributed to the severe abrasive wear that is a consequence of the increased surface roughness caused by sand blasting [36].

In order to further investigate the anti-wear and friction-reducing mechanisms of the GO and OLC as lubricating additives in water, Fig. 8 shows SEM images of the wear surfaces of the smooth discs lubricated with the 0.06-wt.\% GO- and OLC-dispersed water.
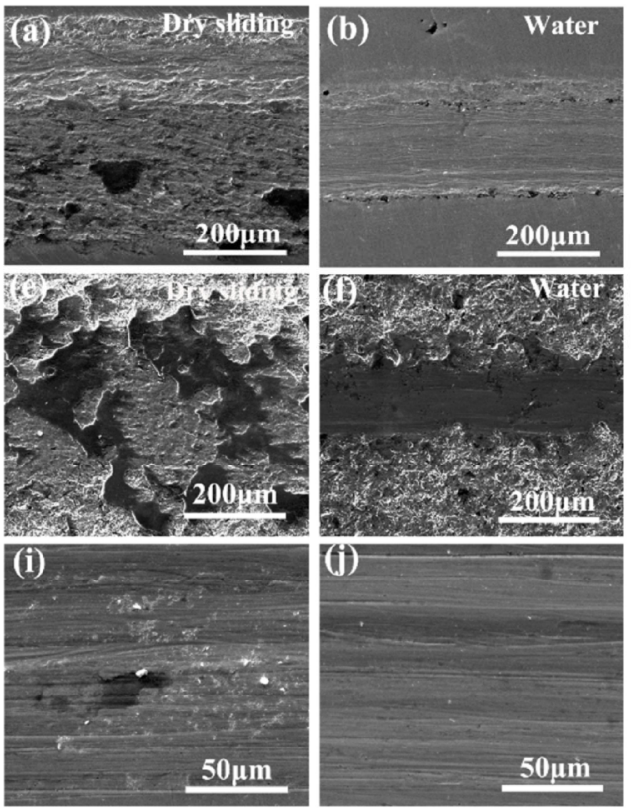
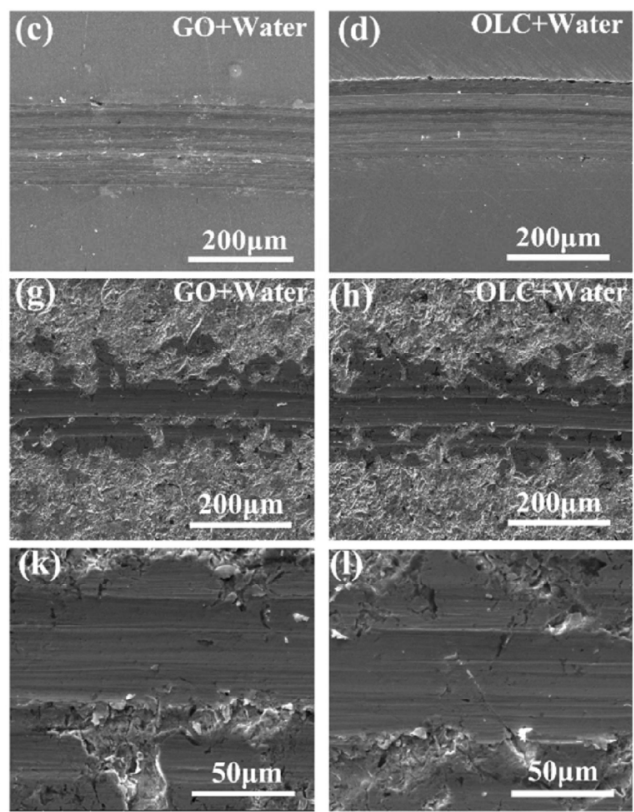

Fig. 7 SEM images of the wear surfaces of the discs under dry sliding and different lubricating conditions. (a-d) the smooth surface; $(\mathrm{e}-\mathrm{h})$ the sand blasted surface; (i), (j), (k), (l) correspond to the magnification of (c), (d), (g), (h), respectively (load: 2 N, additives concentration: $0.06 \mathrm{wt} . \%)$. 

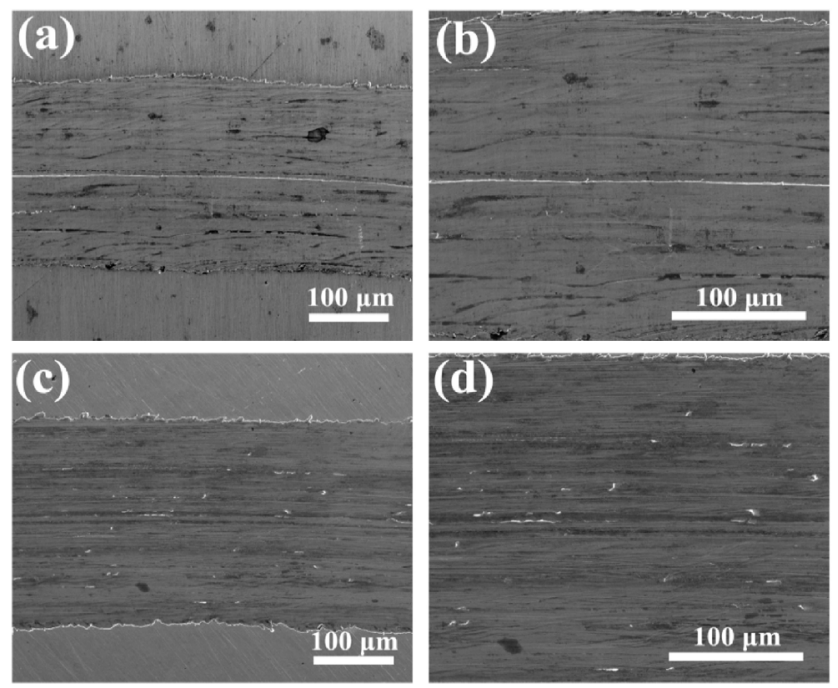

Fig. 8 SEM images of the wear scars on the smooth surfaces lubricated with the 0.06 wt.\% GO $(\mathrm{a}, \mathrm{b})$ and the 0.06 wt.\% OLC (c, d) dispersed water (load: $6 \mathrm{~N}$ ).

After the addition of GO, the wear surface was smooth without deep furrows and scratches (Figs. 8(a) and 8(b)), and the wear scar was relatively narrow and shallow. In contrast, deeper scratches and fragments were observed on the wear surface lubricated by the OLC-dispersed water (Figs. 8(c) and 8(d)). The twodimensional (2D) sheet shape of the GO might easily provide better shear and sliding to protect the surfaces against friction and wear [10], compared to those for the OLC nanoparticles.
The corresponding 2D and three-dimensional (3D) images of the wear tracks are shown in Fig. 9. The wear scar lubricated by the GO-dispersed water (Figs. 9(a) and 9(c)) exhibited smaller wear depth and width than those for the lubrication by the OLCdispersed water (Figs. 9(b) and 9(d)). In addition, Figs. 9(b) and 9(d) show deeper grooves at the bottom of the wear surface lubricated by the OLC-dispersed water, which might be attributed to the generation and accumulation of wear-related debris at the contact interfaces.

Figure 10 shows Raman spectra of the wear scars on the smooth surfaces lubricated by the GO- and OLC-dispersed waters. The D and G peaks of the wear scar lubricated by the GO-dispersed water were consistent with the corresponding peaks of pure GO (Fig. 2(e)), indicating that GO possibly adsorbed on the wear surface and formed a protective film during the sliding process. Compared to the Raman spectrum of the pure GO (Fig. 2(e)), a decrease in density and broadening of the $D$ and $G$ peaks were observed in the spectrum for the wear scar, which might be attributed to the amorphization of the GO during the rubbing process [34]. The typical peaks at $1,339 \mathrm{~cm}^{-1}$ and $1,600 \mathrm{~cm}^{-1}$ were also observed for the wear surface lubricated by the OLC-dispersed water, which indicated that a carbon film formed on the wear surface during the sliding process. Compared with the Raman
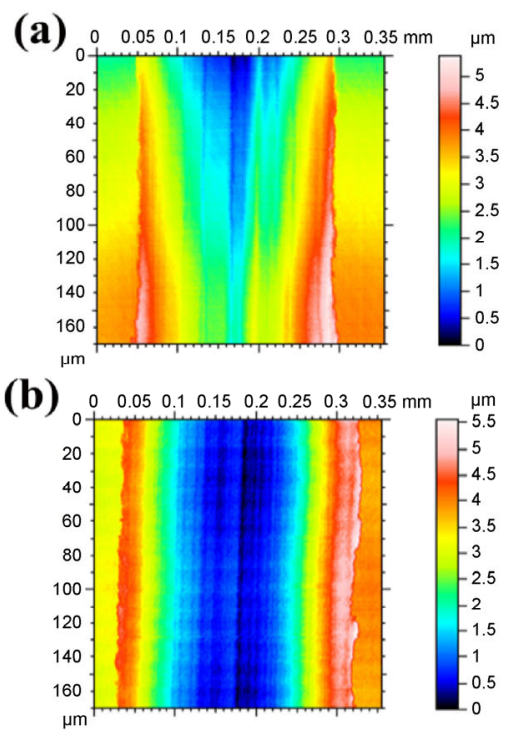
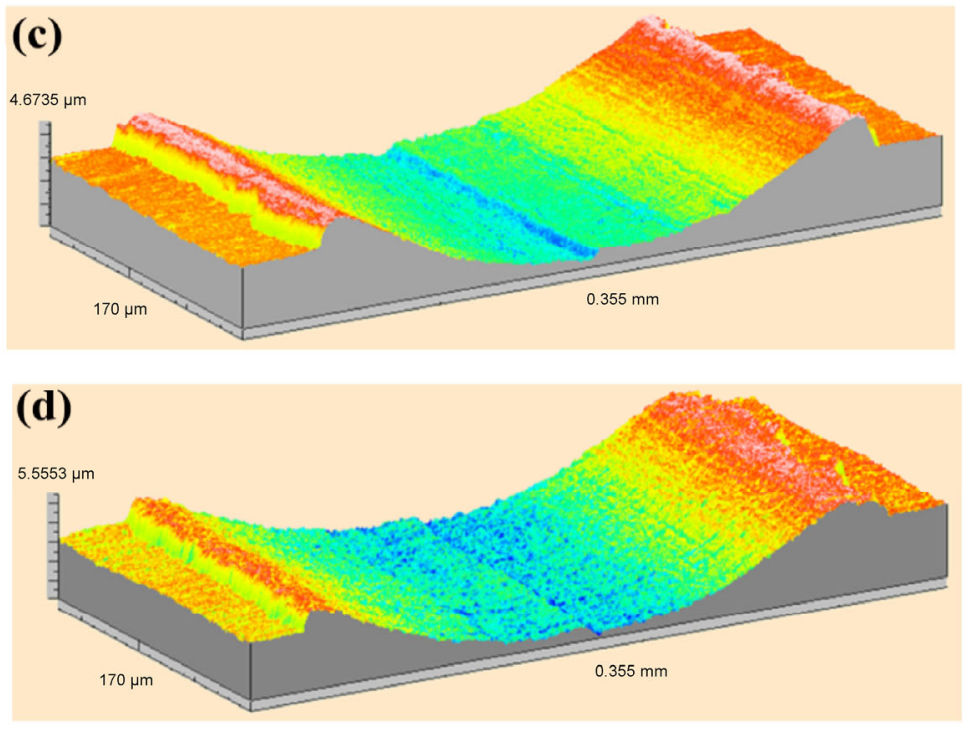

Fig. 9 2D and 3D surface topographies of wear tracks on the smooth surfaces lubricated with the 0.06 wt. \% GO (a, c) and the 0.06 wt.\% OLC $(b, d)$ dispersed water. 


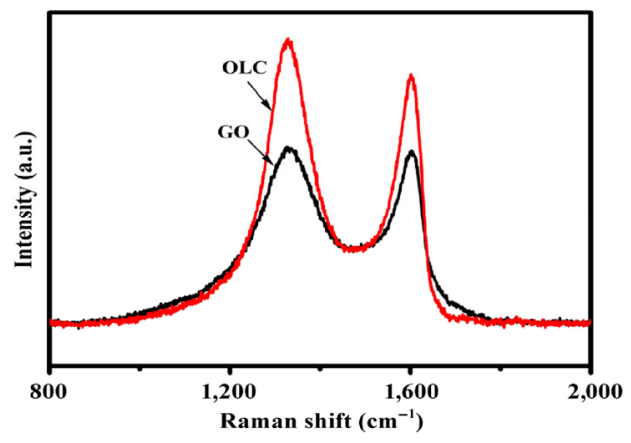

Fig. 10 Raman spectra of the wear scars on the smooth surfaces lubricated with the 0.06 wt.\% GO and the 0.06 wt.\% OLC dispersed water.

spectrum of the OLC (Fig. 2(e)), the intensities of the $D$ and $G$ peaks of the wear scar were increased, associated with the presence of more defects in the OLC after the sliding [37]. The narrower $D$ and $G$ peaks might be attributed to the shear action induced by the graphitization of the OLC during the sliding process [38]. The deposited OLC would be deformed and ruptured by the frictional force and heat during the rubbing process [21, 23].

Figure 11 shows $\mathrm{C} 1 \mathrm{~s}$ and $\mathrm{O} 1 \mathrm{~s}$ XPS spectra of the wear surfaces lubricated with the GO- $(a, b)$ and OLC$(c, d)$ dispersed water. The mass fractions of the $\mathrm{C}, \mathrm{O}$, $\mathrm{Fe}, \mathrm{Cr}$, and Ni elements, determined by XPS, are presented in Table 3. The C 1s XPS spectrum of the wear surface lubricated with the GO-dispersed water (Fig. 11(a)) showed a main peak at $284.5 \mathrm{eV}$ attributed to the graphitic carbon and other peaks associated with oxygen functional groups such as $\mathrm{C}=\mathrm{O}$ bonds in carbonyl $(287.8 \mathrm{eV})$ and C-O bonds in alkoxyl $(285.7 \mathrm{eV})$ groups. Furthermore, the mass fraction $(66.4 \%)$ of the $\mathrm{C}$ element for the wear surface (Table 3) was significantly higher than that in the 304 stainless steel (smaller than $0.08 \%$ ). We can conclude that the GO nanosheets were deposited on the contact surfaces and formed a physical protective film between the two mating surfaces during the sliding process, which is consistent with the results obtained by the Raman spectrum (Fig. 10). As shown in Fig. 11(b), the $\mathrm{Fe}_{3} \mathrm{O}_{4}$ (528.9 eV), $\mathrm{Cr}_{2} \mathrm{O}_{3}(529.8 \mathrm{eV})$, and $\mathrm{NiO}(530.2 \mathrm{eV})$ signals in the $\mathrm{O} 1 \mathrm{~s}$ peak were attributed to the oxidation reactions. The $\mathrm{C}=\mathrm{O}$ signature in the $\mathrm{O} 1$ s peak might originate from the GO lubricant additive. As shown in Fig. 11(c), the C 1s peak of the wear scar surface lubricated with the OLC-dispersed water consisted of three peaks of $\mathrm{C}-\mathrm{C}(284.5 \mathrm{eV}), \mathrm{C}-\mathrm{O}(285.6 \mathrm{eV})$, and $\mathrm{C}=\mathrm{O}(288.1 \mathrm{eV})$ [11]. Similarly, the mass fraction $(51.64 \%)$ of the $C$ element on the wear scar surface (Table 3) was significantly higher than that in the 304 stainless steel (smaller than $0.08 \%$ ), demonstrating that a carbon film was formed on the wear scar during the tribo-test. $\mathrm{C}=\mathrm{O}(530.6 \mathrm{eV}), \mathrm{Fe}_{3} \mathrm{O}_{4}(528.9 \mathrm{eV}), \mathrm{Cr}_{2} \mathrm{O}_{3}$ $(529.8 \mathrm{eV})$, and $\mathrm{NiO}(530.2 \mathrm{eV})$ signatures in the $\mathrm{O} 1 \mathrm{~s}$ peak are observed in Fig. 11(d). The $\mathrm{C}=\mathrm{O}$ signature in the $\mathrm{O} 1 s$ peak originated from the OLC lubricant additive, while those of $\mathrm{Fe}_{3} \mathrm{O}_{4}, \mathrm{Cr}_{2} \mathrm{O}_{3}$, and $\mathrm{NiO}$ originated from the oxidation reactions. As shown in Figs. 11(b) and 11(d) and Table 3, the mass fractions of the $\mathrm{O}, \mathrm{Fe}$, and $\mathrm{Cr}$ elements on the wear surface lubricated with the OLC-dispersed water were significantly higher than those for the surface lubricated with the GO-dispersed water. This result confirmed that the oxidation reaction for the sample lubricated with the OLC additive was significantly stronger than that for the sample lubricated with the GO additive. The OLC particles were more easily destroyed by the
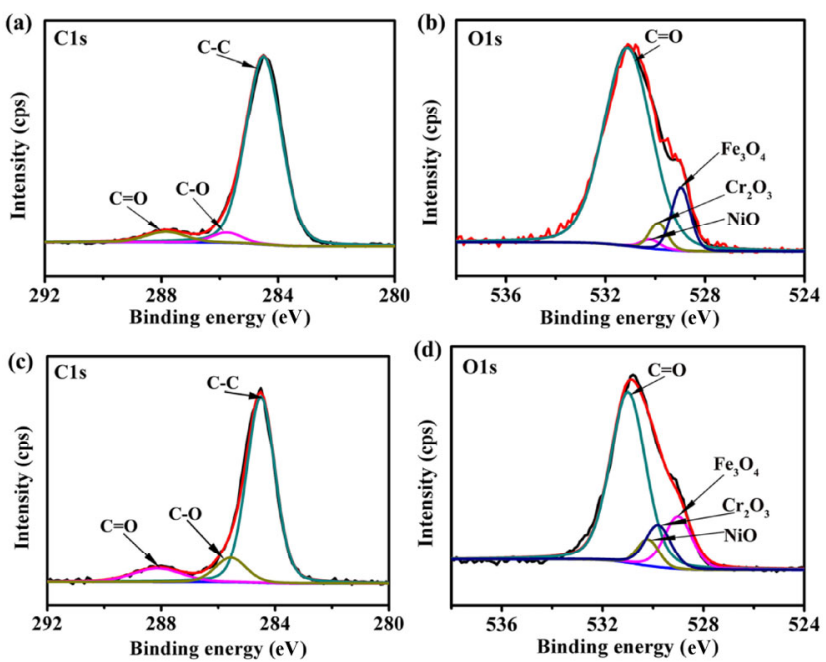

Fig. 11 XPS spectra of C1s and O1s on the wear scars on the smooth surfaces lubricated with the $0.06 \mathrm{wt} . \% \mathrm{GO}(\mathrm{a}, \mathrm{b})$ and the 0.06 wt. \% OLC (c, d) dispersed water.

Table 3 Relative mass fractions of typical elements on the wear scars of the smooth surfaces lubricated with the $0.06 \mathrm{wt} . \% \mathrm{GO}$ and the 0.06 wt.\% OLC dispersed water.

\begin{tabular}{cccccc}
\hline \multirow{2}{*}{$\begin{array}{c}\text { Lubricant } \\
\text { additive }\end{array}$} & \multicolumn{5}{c}{ Mass fraction (wt.\%) } \\
\cline { 2 - 6 } & $\mathrm{C}$ & $\mathrm{O}$ & $\mathrm{Fe}$ & $\mathrm{Cr}$ & $\mathrm{Ni}$ \\
\hline GO & 66.40 & 22.87 & 7.23 & 1.19 & 2.30 \\
OLC & 51.64 & 26.75 & 12.56 & 7.11 & 1.85 \\
\hline
\end{tabular}


frictional force than the GO nanosheets during the rubbing process.

According to the tribo-test results and analyses of the wear scar surfaces, we can conclude that the OLC and GO were successfully employed as lubricant additives in water. For the OLC nanoparticles, the friction-reducing and anti-wear abilities might be attributed to their rolling action mechanism, owing to their onion-like structures and the formation of the lubricating film by the exfoliated graphite sheets during the sliding process. The OLC nanoparticles in water gradually penetrated the interface of the contact surfaces (Figs. 10 and 11) owing to the traction and compression by the contact pressure. The deposited OLC nanoparticles could roll as nanoscale ball bearings to avoid the direct contact of the asperities on the surface $[23,39,40]$. The lubrication mechanism of the GO water-based lubricant additive could be described as follows: The GO nanosheets entered the rubbing surface, as the contact pressure created stressed zones of traction and compression. The gradually accumulated GO nanosheets could fill up the hollows and smoothed the rubbing surface, forming a thin tribofilm with the increase in the sliding distance $[8,10]$. The formed thin tribofilm had important functions, including separation of the two mating metal surfaces to avoid direct contact and bearing of the load from the steel balls. The 2D structure of the GO nanosheets provided better shear and sliding between the two mating surfaces than those in the case of the OLC nanoparticles. The OLC particles might be more easily destroyed by the frictional force than the GO nanosheets during the rubbing process. Consequently, the GO lubricant additive in water exhibited a better lubricating performance than that of the OLC, particularly under a high applied load.

\section{Conclusions}

Thin GO nanosheets and OLC nanoparticles with diameters of 30-60 nm were successfully synthesized from natural graphite powder and candle soot, respectively. The lubricating performances of the resulting GO and OLC as lubricant additives in water were evaluated under different sliding conditions. In addition, the effects of sand blasting on the morphologies and tribological properties of the treated disc were evaluated.
As expected, the OLC and GO as lubricating additives in water significantly reduced the friction coefficients and wear rates of the sliding disc, which is independent of the disc surface treatment. Overall, GO is observed to exhibit superior friction-reducing and anti-wear abilities compared to those of the OLC as water-based lubricant additives - a trace amount of GO could achieve lubricating abilities equivalent to those for an abundant amount of OLC. Although sand blasting increased the hardness of the treated disc, its surface roughness significantly increased leading to its poor wear resistance under different sliding conditions. The friction-reduction and anti-wear abilities of OLC in water might be attributed to its onion-like structure that produces rolling action and the formation of the tribofilm during the sliding process. The excellent lubricating ability of the GO was attributed to the formation of thin protective films on the contact surfaces and its 2D structure providing better shear and sliding between the two mating wear surfaces.

\section{Acknowledgements}

The authors are grateful to the financial support of the National Natural Science Foundation of China (No. 21473061), the Guangdong Natural Science Funds for Distinguished Young Scholar (No. 2015A030306026), and the Science and Technology Planning Project of Guangzhou City (No. 201707010055).

Open Access: The articles published in this journal are distributed under the terms of the Creative Commons Attribution 4.0 International License (http:// creativecommons.org/licenses/by/4.0/), which permits unrestricted use, distribution, and reproduction in any medium, provided you give appropriate credit to the original author(s) and the source, provide a link to the Creative Commons license, and indicate if changes were made.

\section{References}

[1] Ma H B, Li J, Chen H, Zuo G Z, Yu Y, Ren T H, Zhao Y D. XPS and XANES characteristics of tribofilms and thermal films generated by two P- and/or S-containing additives in water-based lubricant. Tribology International 42(6): 940-945 (2009) 
[2] Wang W, Xie G X, Luo J B. Black phosphorus as a new lubricant. Friction 6(1): 116-142 (2018)

[3] Amann T, Gatti F, Oberle N, Kailer A, Rühe J. Galvanically induced potentials to enable minimal tribochemical wear of stainless steel lubricated with sodium chloride and ionic liquid aqueous solution. Friction 6(2): 230-242 (2018)

[4] Golchin A, Wikner A, Emami N. An investigation into tribological behaviour of multi-walled carbon nanotube/ graphene oxide reinforced UHMWPE in water lubricated contacts. Tribology International 95: 156-161 (2016)

[5] Peng Y T, Hu Y Z, Wang H. Tribological behaviors of surfactant-functionalized carbon nanotubes as lubricant additive in water. Tribology Letters 25(3): 247-253 (2006)

[6] Kinoshita H, Nishina Y, Alias A A, Fujii M. Tribological properties of monolayer graphene oxide sheets as waterbased lubricant additives. Carbon 66: 720-723 (2014)

[7] Elomaa O, Singh V K, Iyer A, Hakala T J, Koskinen J. Graphene oxide in water lubrication on diamond-like carbon vs. stainless steel high-load contacts. Diamond and Related Materials 52: 43-48 (2015)

[8] Ye X Y, Ma L M, Yang Z G, Wang J Q, Wang H G, Yang S R. Covalent Functionalization of Fluorinated Graphene and Subsequent Application as Water-based Lubricant Additive. ACS Appl Mater Interfaces 8(11): 7483-7488 (2016)

[9] Liu Y H, Wang X K, Pan G S, Luo J B. A comparative study between graphene oxide and diamond nanoparticles as water-based lubricating additives. Science China Technological Sciences 56(1): 152-157 (2012)

[10] Song H J, Li N. Frictional behavior of oxide graphene nanosheets as water-base lubricant additive. Applied Physics A 105(4): 827-832 (2011)

[11] Jiang L W, Wang Z H, Geng D Y, Lin Y M, Wang Y, An J, He J, Li D, Liu W, Zhang Z D. Structure and electromagnetic properties of both regular and defective onion-like carbon nanoparticles. Carbon 95: 910-918 (2015)

[12] Liu X G, Or S W, Jin C G, Lv Y H, Feng C, Sun Y P. NiO/C nanocapsules with onion-like carbon shell as anode material for lithium ion batteries. Carbon 60: 215-220 (2013)

[13] Pech D, Brunet M, Durou H, Huang P H, Mochalin V, Gogotsi Y, Tabera P L, Simon P. Ultrahigh-power micrometresized supercapacitors based on onion-like carbon. Nature Nanotechnology 5(9): 651-654 (2010)

[14] Bushueva E G, Galkin P S, Okotrub A V, Bulusheva L G, Gavrilov N N, Kuznetsov V L, Moiseekov, S L. Double layer supercapacitor properties of onion-like carbon materials. Physica Status Solidi B 245(10): 2296-2299 (2008)

[15] Su D S, Maksimova N I, Mestl G, Kuznetsov V L, Keller V, Schlögl R, Keller Nicolas. Oxidative dehydrogenation of ethylbenzene to styrene over ultra-dispersed diamond and onion-like carbon. Carbon 45(11): 2145-2151 (2007)
[16] Kuznetsov V L, Butenko Y V, Chuvilin A L, Romanenko A I, Okotrub A V. Electrical resistivity of graphitized ultradisperse diamond and onion-like carbon. Chemical Physics Letters 336(5-6): 397-404 (2001)

[17] Matsumoto N, Mistry K K, Kim J H, Eryilmaz O L, Erdemir A, Kinoshita H, Ohmae N. Friction reducing properties of onion-like carbon based lubricant under high contact pressure. Tribology-Materials, Surfaces \& Interfaces 6(3): 116-120 (2013)

[18] Joly-Pottuz L, Bucholz E W, Matsumoto N, Phillpot S R, Sinnott S B, Ohmae N, Matin J M. Friction Properties of Carbon Nano-Onions from Experiment and Computer Simulations. Tribology Letters 37(1): 75-81 (2009)

[19] Yao Y L, Wang X M, Guo J J, Yang X W, Xu B S. Tribological property of onion-like fullerenes as lubricant additive. Materials Letters 62(16): 2524-2527 (2008)

[20] Joly-Pottuz L, Matsumoto N, Kinoshita H, Vacher B, Belin M, Montagnac G, Matin J M, Ohmae N. Diamond-derived carbon onions as lubricant additives. Tribology International 41(2): 69-78 (2008)

[21] Joly-Pottuz L, Vacher B, Ohmae N, Martin J M, Epicier T. Anti-wear and friction reducing mechanisms of carbon nano-onions as lubricant additives. Tribology Letters 30(1): 69-80 (2008)

[22] Hirata A, Igarashi M, Kaito T. Study on solid lubricant properties of carbon onions produced by heat treatment of diamond clusters or particles. Tribology International 37(11-12): 899-905 (2004)

[23] Wei J X, Cai M R, Zhou F, Liu W M. Candle soot as particular lubricant additives. Tribology Letters 53(3): 521-531 (2014)

[24] Nouveau C, Labidi C, Collet R, Benlatreche Y, Djouadi M A. Effect of surface finishing such as sand-blasting and CrAlN hard coatings on the cutting edge's peeling tools' wear resistance. Wear 267(5-8): 1062-1067(2009)

[25] Guan X S, Dong Z F, Li D Y. Surface nanocrystallization by sand blasting and annealing for improved mechanical and tribological properties. Nanotechnology 16: 2963-2971 (2005)

[26] Wu T-T, Ting J-M. Preparation and characteristics of graphene oxide and its thin films. Surface and Coatings Technology 231: 487-491 (2013)

[27] Hummers Jr W S, Offeman R E. Preparation of graphitic oxide. Journal of the American Chemical Society 80(6): 1339-1339 (1958)

[28] Meng Y, Su F H, Chen Y Z. A Novel Nanomaterial of graphene oxide dotted with $\mathrm{Ni}$ nanoparticles produced by supercritical $\mathrm{CO}_{2}$-assisted deposition for reducing friction and wear. ACS Appl Mater Interfaces 7(21): 11604-11612 (2015) 
[29] Choucair M, Stride J A. The gram-scale synthesis of carbon onions. Carbon 50(3): 1109-1115 (2012)

[30] Eda G, Chhowalla M. Chemically derived graphene oxide: towards large-area thin-film electronics and optoelectronics. Advanced Materials 22(22): 2392-2415 (2010)

[31] He C N, Zhao N Q, Shi C S, Du X W, Li J J, Cui L. A practical method for the production of hollow carbon onion particles. Journal of Alloys and Compounds 425(1-2): 329-333 (2006)

[32] Baraket M, Walton S G, Wei Z, Lock E H, Robinson J T, Sheehan P. Reduction of graphene oxide by electron beam generated plasmas produced in methane/argon mixtures. Carbon 48 (12): 3382-3390 (2010)

[33] Krishnamoorthy K, Veerapandian M, Mohan R, Kim S-J. Investigation of Raman and photoluminescence studies of reduced graphene oxide sheets. Applied Physics A 106(3): 501-506 (2011)

[34] Krishnamoorthy K, Veerapandian M, Yun K, Kim S J. The chemical and structural analysis of graphene oxide with different degrees of oxidation. Carbon 53: 38-49 (2013)

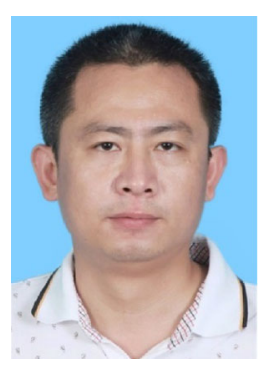

Fenghua SU. He received his $\mathrm{PhD}$ degree from Lanzhou Institute of Chemical Physics, Chinese Academy of Sciences in 2007. He joined School of Mechanical and Automotive Engineering, South China University of Technology from 2007. His current position is a professor of South China University of Technology. At present, his
[35] Jiang X P, Wang X Y, Li J X, Li D Y, Man C S, Shepard M J, Zhai T. Enhancement of fatigue and corrosion properties of pure Ti by sandblasting. Materials Science and Engineering A 429(1-2): 30-35 (2006)

[36] Wang J Z, Yan F Y, Xue Q J. Tribological behavior of PTFE sliding against steel in sea water. Wear 267(9-10): 1634-1641 (2009)

[37] Barros E B, Demir N S, Souza Filho A G, Mendes Filho J, Jorio A, Dresselhaus G, Dresselhaus M S. Raman spectroscopy of graphitic foams. Physical Review B 71(16): 165422 (2005)

[38] Yoshida A, Kaburagi Y, Hishiyama Y. Full width at half maximum intensity of the $G$ band in the first order Raman spectrum of carbon material as a parameter for graphitization. Carbon 44(11): 2333-2335 (2006)

[39] Wu Y Y, Tsui W C, Liu T C. Experimental analysis of tribological properties of lubricating oils with nanoparticle additives. Wear 262(7-8): 819-825 (2007)

[40] Bucholz E W, Phillpot S R, Sinnott S B. Molecular dynamics investigation of the lubrication mechanism of carbon nanoonions. Computational Materials Science 54: 91-96 (2012)

research areas cover the application of the advanced materials in tribology, interfacial phenomenon of mechanical components, and advanced manufacturing technology. He has published more than 60 SCI papers in various reputed journals such as Small, ACS Applied Materials \& Interfaces, Scientific Reports, Tribology International, etc. The published papers have been cited over 1,000 times by other decent SCI publications in the past a few years. 